\title{
Robust Controlling of Thermal Mixing Procedure by Means of Sliding Type Controlling
}

\author{
Dharmendra Singh
}

\begin{abstract}
The thermal mixing robust controlling ideas by employing slider controlling method employed in this work. It is envisioned for designing a Slider Controlling Mode for achieving reference temp. of mixer in existence of unsettling noises. The process performance is traced by MATLAB environment simulation. The constructed controlling model ensures that the stability and convergence requirement in existence of conflicts \& later demonstrates its robust property. The result of offered process compared with classical PID controlling process that illustrates the process is successful and simple for a wide-ranging span of functioning conditions, structure variabilities \& nonlinear dynamics of the model.
\end{abstract}

Keywords: Slider Mode Controlling (SMC), PID controlling, liquid mixing, FOPDT model.

\section{INTRODUCTION}

Generally mixers are employed in "pharmaceuticals", "chemicals", "food processing industries" for providing multiple substrate with higher quality included[1]. Because of inherent non-linear qualities, plant uncertainties existence and lack of continuous working condition, chemical controlling methods such as tank mixing had been an attractive engineer controlling subjects. The mixing problem related to content measurement of hot and cold water for desired temperature should be well known to everybody, including those who are not related to controlling specialists. This is an issue that is illustrated in industries as well in everyday shower case. In this work we study the "First Order plus Dead Time Model (FOPDT)" [2] of mixing tank and applying a robust controlling method for attaining a desired chamber temp. "Sliding Mode Control (SMC)"[3] is able to control non-linear models due to its robust nature of another uncertainties and parameter variations. Utilization of SMCs in multiple chemical methods had been accounted.

\section{Practice}

The mixing is a very vital practice for quality generation of the products in processing industry. Multiple reactants are combined in multiple concentrations for producing products of multiple qualities that are employed for further process[4]. According to few cases, a little change in the process of synthesis can result a bad quality yield. The mixer consisting of mixing tank, a valves and stirrer wherein a cold and hot water fluxes are mixed together. The objects of the method is to raise the temp of chamber up to its fixed point.

\section{CONTROLLERS}

\section{i. PID Controller}

PID, PI or P are ordinarily employed controllers in manufacturing industries. The PID controller is defined by[5]:

Here e denotes the output constraints deviation, $x(t)$ through the reference constraints, $r(t)$. The error as

$\mathrm{e}(\mathrm{t})=\mathrm{r}(\mathrm{t})-\mathrm{x}(\mathrm{t})(2)$

$u(t)$ the controlling signal is total of three expressions, the expression in relation with error $\mathrm{e}(\mathrm{t})$ is a relative expression, the expression in relation with the integral term due to error integral and the deviation term analogous with the error derivative. The proportional term ensures its stability[6]. But the offset error is observed in output through action of proportion. The offset can be abolished through integral expressions on other hand it enhances settling time and overshoot, which can be reduced by increasing derivative time. The damping can be achieved in response by derivative terms[7].

\section{ii. $\quad$ Sliding Mode Controller}

Sliding mode controller is a rhobust non-linear controlling technique. This technology is suitable for nonlinear dynamical working model under uncertainty condition such as variable constraints, uncertainty in modelling and outer distractions.

The "Sliding Mode Controlling" technology is simple and is indifferent for matching and magnifications at outcome. This can be used broadly for reducing modelling order of factory dynamics and had a finite-time junction[8].

The evolution of "Sliding Mode Controller" attained from VSC.

The SMC technology model is employed for clustering a sliding surface alongside the trajectory model slides at its point of equilibrium. A discrete controlling law can be derived from the model of trajectory on the sliding surface and further slides along with surface of final equilibrium point. The constructional process including dual steps. Initially planning its sliding surface as per desire for ensuring model stability and secondly applying the controlling law according to the models planning that converges into sliding surface in fixed period[9]. 


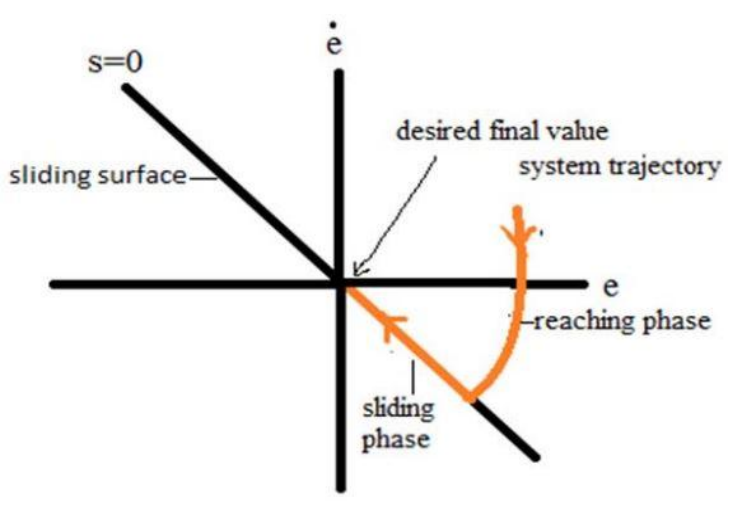

Fig. 1: The Concept of Sliding Mode Control

To the degree compound procedures are concerned initially, developing a total model is inconvenient due to the unusualness of the procedure and different obscure parameters influencing the procedure. Also, besides, scientific conditions depicting the procedure elements are for the most part of higher request. The paper introduces a suitable methodology using a decreased request model of the synthetic procedure[10].

The sliding surface equation is stated from FOPDT system of the method.

The equation for sliding surface is an integro-differential of error equation that is provided by

$$
S(t)=\left(\frac{d}{d t}+\lambda\right)^{n} \int_{0}^{t} e(t) d t
$$

Here $\mathrm{e}(\mathrm{t})$ is denotes tracking error.

The constraints $\lambda$ selects the performance of model on sliding surface, here model is of $n$ order. The motive of controlling is ensuring the output almost equivalent to the set point at every time of instants, and error and its differentiated at $\mathrm{t}=0$. At the reference point, $\mathrm{S}(\mathrm{t})$ became a constant value[11]. For maintaining a continuous value of $\mathrm{S}(\mathrm{t})$, e $(\mathrm{t})$ should be zero for whole period of time that denotes

$$
\frac{d}{d t} S(t)=0
$$

Once the sliding surface is designed, the control law is derived which directs the system trajectory to its final equilibrium point and satisfies (4). The SM Control law, $u(t)$, consists of a continuous part, $\mathrm{u}_{\mathrm{c}}(\mathrm{t})$, and a discrete part, $\mathrm{u}_{\mathrm{d}}(\mathrm{t})$. That is

$$
u(t)=u_{c}(t)+u_{d}(t)
$$

The continuous part is a function of the controlled variable, $\mathrm{x}(\mathrm{t})$, and the reference variable, $\mathrm{r}(\mathrm{t})$ and is given by

$$
\left.u_{c}(t)=\dot{f(x}(t), r(t)\right)
$$

The discontinuous part, $\mathrm{u}_{\mathrm{d}}(\mathrm{t})$ involves a switching function and switches about the sliding surface.

$$
u_{d}(t)=K_{d} \frac{S(t)}{|S(t)|+\delta}
$$

where $K_{d}$ is the controller gain responsible for the reaching phase. $\delta$ is the parameter responsible to eliminate chattering. Chattering is an undesirable high frequency oscillation in sliding motion which degrades the control objective. Perfect tracking can be achieved by reducing chattering. Thus the control law directs the system trajectory to the sliding surface, and then proceeds until the equilibrium state is reached.

\section{CONTROLLER CONSTRUCTING}

i. $\quad$ SMCR construction on the basis of FOPDT system from the procedure:

In this part, the structure of SMCR for process regulation on FOPDT structure of the real procedure is mapped[12].

The first order plus dead time approximation of the system is given by

$$
\frac{X(s)}{U(s)}=\frac{K_{1} e^{-t_{0} s}}{\tau s+1}
$$

Here Laplace of controlling constant $\mathrm{X}(\mathrm{s})$ and $\mathrm{U}(\mathrm{s})$ are deviation constant. The structure constraints that is procedure gain, $\mathrm{K} 1$, procedure time constant, and procedure dead time, t 0 are utilized for attaining theinitial evaluations of the tuning parameters of SMCR.

The controlling is established by employing a decreased order of structure equation is calculated by utilizing "first order Taylor series" estimation[13].

$$
e^{-t_{0} s}=\frac{1}{t_{0} s+1}
$$

\section{IMPROVEMENT IN SMCR BY USING FIRST ORDER TAYLOR SERIES ESTIMATION}

Applying Taylor series expansion and substituting (9) in (8) gives

$$
\frac{X(s)}{U(s)}=\frac{K_{1}}{(\tau s+1)\left(t_{0} s+1\right)}
$$

In differential equation form,

$$
t_{0} \tau \ddot{x}+\left(t_{0}+\tau\right) \dot{x}+x=k u
$$

and since this is a second order differential equation, $n=2$, from (3) S becomes

$$
S=\dot{e}+2 \lambda e+\lambda^{2} \int_{0}^{t} e d t(12)
$$

From Eq. (4)

$$
\dot{S}=\ddot{e}+2 \lambda \dot{e}+\lambda^{2} e=0(13)
$$

Substituting $\mathrm{e}=\mathrm{r}-\mathrm{x}$, in the first term of equation (13) yields

$$
(\ddot{r}-\ddot{x})+2 \lambda e+\lambda^{2} e=0
$$

Solving $(9)$ and substituting it in (12) gives $u_{c}$, the continuous part of the control law as 


$$
u_{C}=\left(\frac{t_{0}+\tau}{t_{0} \tau}\right)\left[\left(\frac{t_{0}+\tau}{t_{0} \tau} \dot{x}+\frac{x}{t_{0} \tau}+\lambda^{2} e+\ddot{r}+\lambda^{2} \dot{r}\right]\right.
$$

The procedure of deriving the expression for the continuous part of the control law from (12) and (14) is known as the equivalent control procedure in SMC theory [2].

The derivative of the reference value gives zero. Thus,

$$
u_{C}=\left(\frac{t_{0}+\tau}{K_{1}}\right)\left[\left(\frac{t_{0}+\tau}{t_{0} \tau}-2 \lambda\right) \dot{x}+\frac{x}{t_{0} \tau}+\lambda^{2} e\right](16)
$$

$\lambda$ for the continuous part of the controller [12] is considered

$$
\lambda=\frac{t_{0}+\tau}{2 t_{0} \tau}
$$

Thus, the control law can be represented as

$$
\begin{aligned}
& u=\left(\frac{t_{0} \tau}{K_{1}}\right)\left(\frac{x}{t_{0} \tau}+\lambda^{2} e\right)+K_{d} \frac{s}{|S|+\delta} \\
& \text { With } \mathrm{S}=\operatorname{sign}\left(\mathrm{K}_{1}\right)\left[-\dot{x}+2 \lambda e+\lambda^{2} \int_{0}^{t} e d t\right]
\end{aligned}
$$

Equations (18) and (19) constitute the controller equations of the $\mathrm{SMCr}$ consisting of the tuning parameters and the characteristic parameters of the FOPDT model. The term $\operatorname{sign}\left(\mathrm{K}_{1}\right)$ is incorporated in the sliding surface equation (19) which accounts for the process gain and hence the effect of the controller.

\section{SIMULATION\& RESULTS}

The mixing chamber receives a hot fluid with heavy flow rate $\mathrm{FH}(\mathrm{t})$ and a colder liquid having mass flow rate $\mathrm{FC}(\mathrm{t})$ being completed. The temp. sensor is embedded $120 \mathrm{ft}$ under stream to the chamber where measuring of flow is required. The temp. sensor is calibrated for a interval of 100 to 200 $\mathrm{oF}[14]$. The referencing of the temp is performed at $150 \mathrm{oF}$. the flow of the hot water is altered from $250 \mathrm{lb} / \mathrm{min}$ to 220 $\mathrm{lb} / \mathrm{min}$, further to $190 \mathrm{lb} / \mathrm{min}$, after $160 \mathrm{lb} / \mathrm{min}$ and at the end to $130 \mathrm{lb} / \mathrm{min}$.

The structure is linearized by the plant as considered as presumptions as follows:

- Volume of the liquid is attained as constant.

- Mixing of the liquid into the chamber is performed very sincerely.

- Insulation of the chamber and pipeline is performed properly.

The implementation of the designed sliding mode controller is exhibited in this paper.

The steady state values and design parameters for the system are listed in Table 1 [1].

The equations constituting the dynamic model of mixing tank are given as follows [1]:

Energy balance equation of the tank $F_{H}(t) C_{P H} T_{H}(t)+F_{C}(t) C_{P C} T_{C}(t)-\left(F_{H}(t)+F_{C}(t)\right) C_{P T} T_{T}(t)$

$$
=V \rho C_{P T} \frac{d T_{T}(t)}{d t}
$$

Tank temperature after transportation delay

$T_{T d}(t)=T_{T}\left(t-t_{d}\right)$
Transportation delay

$$
t_{d}=\frac{L A \rho}{F_{H}(t)+F_{C}(t)}
$$

Transmitter output

$$
\frac{d T t(t)}{d t}=\frac{1}{\tau_{t}}\left[\frac{T_{T d}(t)-100}{100}-T t(t)\right]
$$

Equation for the position of valve

$$
\frac{d V_{X}(t)}{d t}=\frac{1}{\tau_{V P}}\left[m(t)-V_{X}(t)\right]
$$

Equation for valve

$$
F_{C}(t)=\frac{500}{60} C_{V F} V_{X}(t) \sqrt{g \Delta P}
$$

Sliding mode controller

$$
u=u_{c}+u_{d}
$$

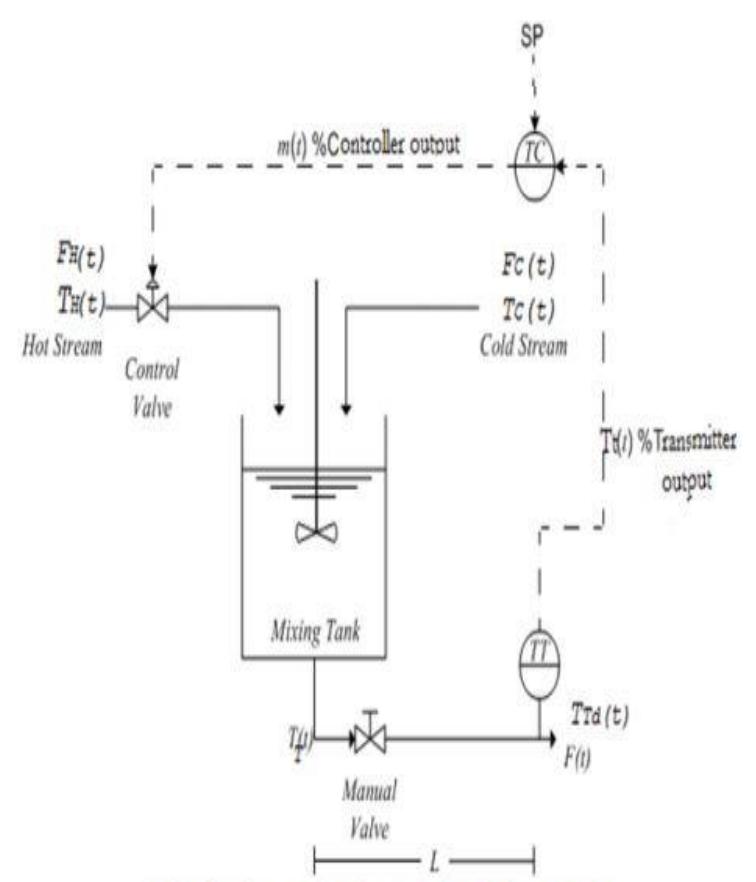

Fig. 2: Control scheme of mixing tank 
Table 1: Process parameters and steady-state values [1]

\begin{tabular}{|l|l|l|}
\hline \multicolumn{1}{|c|}{ Parameter } & Variable & \multicolumn{1}{c|}{ Value } \\
\hline Hot fluid outflow & $\mathrm{F}_{\mathrm{H}}$ & $250.0 \mathrm{lb} / \mathrm{min}$ \\
\hline Cold fluid oufflow & $\mathrm{F}_{\mathrm{C}}$ & $190.0 \mathrm{lb} / \mathrm{min}$ \\
\hline Temperature of hot fluid & $\mathrm{T}_{\mathrm{H}}$ & $250.0^{\circ} \mathrm{F}$ \\
\hline Temperature of cold fluid & $\mathrm{T}_{\mathrm{C}}$ & $50.0^{\circ} \mathrm{F}$ \\
\hline Temperature of mixed fluid & $\mathrm{T}_{\mathrm{T}}$ & $150.0^{\circ} \mathrm{F}$ \\
\hline Volume of fluid in tank & $\mathrm{V}$ & $15 \mathrm{ft}^{3}$ \\
\hline $\begin{array}{l}\text { Heat capacity at constant pressure } \\
\text { of hot fluid }\end{array}$ & $\mathrm{C}_{\mathrm{PH}}$ & $0.8 \mathrm{Btu} / \mathrm{b}-{ }^{\circ} \mathrm{F}$ \\
\hline $\begin{array}{l}\text { Heat capacity at constant pressure } \\
\text { of cold fluid }\end{array}$ & $\mathrm{C}_{\mathrm{PC}}$ & $1.0 \mathrm{Btu} / \mathrm{b}-{ }^{\circ} \mathrm{F}$ \\
\hline $\begin{array}{l}\text { Heat capacity at constant volume } \\
\text { of mixed fluid }\end{array}$ & $\mathrm{C}_{\mathrm{PT}}$ & $0.9 \mathrm{Btu} / \mathrm{b}-{ }^{\circ} \mathrm{F}$ \\
\hline Mixed fluid density & $\rho$ & $62.4 \mathrm{lb} / \mathrm{t}^{3}$ \\
\hline Cross section of pipe & $\mathrm{A}$ & $0.2006 \mathrm{ft}$ \\
\hline Length of pipe & $\mathrm{L}$ & $120 \mathrm{ft}$ \\
\hline Coefficient of valve flow & $\mathrm{C}_{\mathrm{VF}}$ & $12 \mathrm{gpm} / \mathrm{psi} \mathrm{si}^{\mathrm{I}}$ \\
\hline Reference temperature & $\mathrm{T}_{\mathrm{ref}}$ & $150^{\circ} \mathrm{F}$ \\
\hline $\begin{array}{l}\text { Time constant of the temperature } \\
\text { transmitter }\end{array}$ & $\mathrm{T}$ & $0.5 \mathrm{~min}$ \\
\hline Time constant of the control valve & $\mathrm{VP}$ & $0.4 \mathrm{~min}$ \\
\hline Transmitter output & $\mathrm{T}_{\mathrm{t}}$ & $0-1$ \\
\hline Specific gravity & $\mathrm{g}$ & 1 \\
\hline Pressure difference across valve & $\Delta \mathrm{P}$ & $16 \mathrm{psi}$ \\
\hline Controller output & $\mathrm{m}(\mathrm{t})$ & $0-1$ \\
\hline Valve position & $\mathrm{V}_{\mathrm{X}}$ & 0.478 \\
\hline
\end{tabular}

The temp. controlling for mixing chamber is studied by employing dual controlling schemes: i. utilizing prior PID controller ii. Employing sliding mode controlling and the result analysis is performed. The SMC controller had been constructed for a PID sliding surface.

The model is simulated in MATLAB platform[15].

To study the property robustness of SMC, noise is added into the model as a step deviation in hot fluid flow as illustrated in Figure.3. this illustrates the maintenance of temp of the mixed liquid coming out of the chamber at $150 \mathrm{oF}$ that is performed with manipulation of cold liquid.
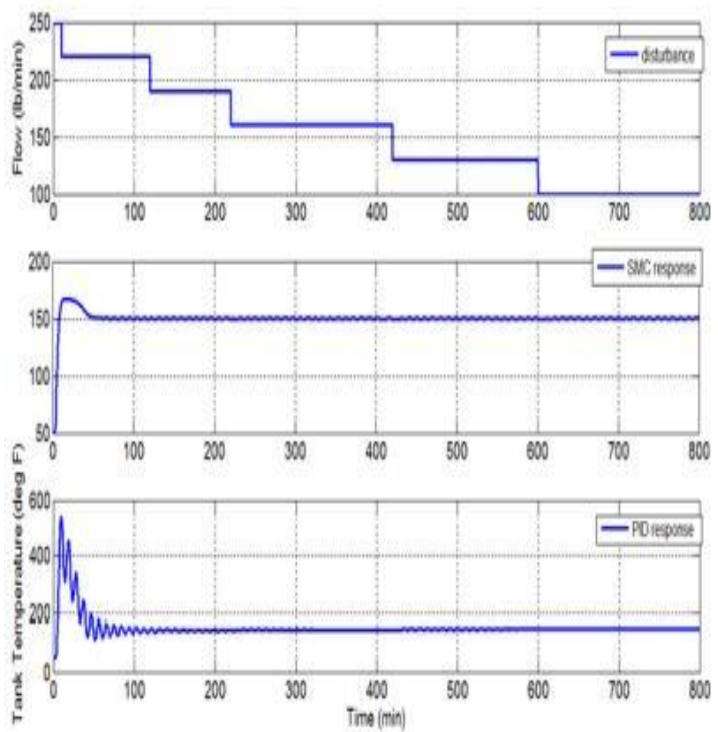

Fig. 3: Disturbance and Response
It is evident from Fig. 3. that the response of the conventional PID controller is not up to the mark owing to the variation in the hot fluid flow. On the other hand the Sliding Mode Controller maintains its robustness and stability despite being affected by the disturbances as mentioned above.

The convergence of error is given in Fig. 4.

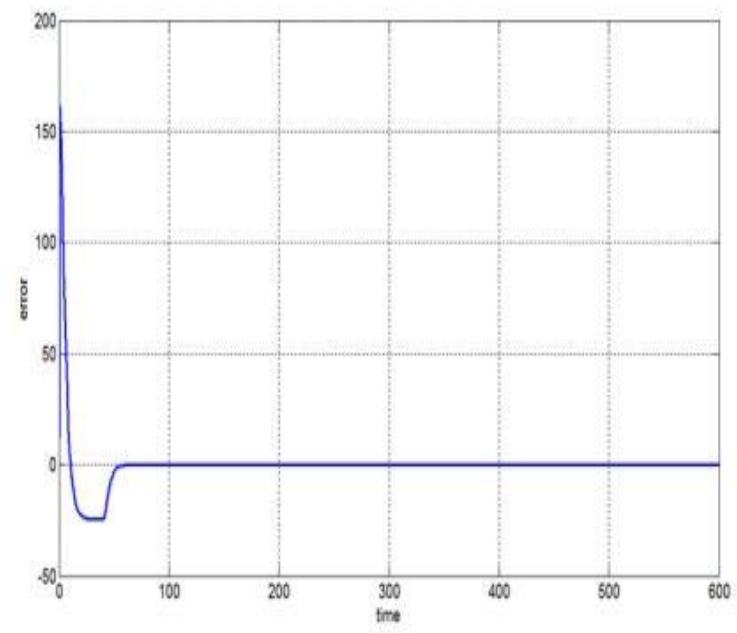

Fig. 4: Error vs Time

\section{CONCLUSIONS}

This paper determines the construction of a controller on the basis of "SLIDING MODE" technology from the FOPDT structure of thermally collaborating chamber for controlling temp of the liquid of the chamber. The result of model proves that the SMC is extremely strong in comparison with prior PID controllers that controls nonlinear chemical procedure through decreased order model. The outcome is represented into the paper that states the robust characteristics of the sliding mode technology with existence of non-linearity and disquiets. Simulation is performed for adding disturbance to the stream of hot liquid and the controlling performance is set up to be efficient.

\section{REFERENCES}

1. Y. K. Suh and S. Kang, "A review on mixing in microfluidics," Micromachines. 2010.

2. F. Padula and A. Visioli, "Tuning rules for optimal PID and fractional-order PID controllers," J. Process Control, 2011.

3. Y. Shtessel, C. Edwards, L. Fridman, and A. Levant, Sliding mode control and observation. 2014.

4. F. De Ridder and M. Coomans, "Grey-box model and identification procedure for domestic thermal storage vessels," Appl. Therm. Eng., 2014.

5. T. M. P. Nguyen, M. R. Petrizzo, and R. P. Speijer, "Experimental dissolution of a fossil foraminiferal assemblage (Paleocene-Eocene Thermal Maximum, Dababiya, Egypt): Implications for paleoenvironmental reconstructions," Mar. Micropaleontol., 2009.

6. S. M. Pourmortazavi, S. S. Hajimirsadeghi, M. RahimiNasrabadi, and M. M. Zahedi, "Taguchi robust design to optimize synthesis of lead oxalate nano-disks," Mater.

Published By:

Blue Eyes Intelligence Engineering

\& Sciences Publication 
Sci. Semicond. Process., 2013.

7. Y. MURAKAMI, "PID Controller," Rev. Laser Eng., 2015.

8. L. J. Zhang, H. M. Jia, and D. P. Jiang, "Sliding mode prediction control for 3D path following of an underactuated AUV," in IFAC Proceedings Volumes (IFAC-PapersOnline), 2014.

9. N. Colombani, B. M. S. Giambastiani, and M. Mastrocicco, "Combined use of heat and saline tracer to estimate aquifer properties in a forced gradient test," $J$. Hydrol., 2015.

10. S. Sadeghi, A. Zehtab Yazdi, and U. Sundararaj, "Controlling Short-Range Interactions by Tuning Surface Chemistry in HDPE/Graphene Nanoribbon Nanocomposites," J. Phys. Chem. B, 2015.

11. S. M. Pourmortazavi, S. Babaee, Z. Marashianpour, and I. Kohsari, "Stabilizing of magnesium powder by microencapsulation with azidodeoxy cellulose nitrate," Prog. Org. Coatings, 2015.

12. K. Krishnan and G. Karpagam, "Comparison of PID Controller Tuning Techniques for a FOPDT System," Int. J. Curr. Eng. Technol., 2014.

13. A. I. de Castro, J. Six, R. E. Plant, and J. M. Peña, "Mapping crop calendar events and phenology-related metrics at the parcel level by object-based image analysis (OBIA) of MODIS-NDVI time-series: A case study in central California," Remote Sens., 2018.

14. M. Gwerder, D. Gyalistras, C. Sagerschnig, R. S. Smith, and D. Sturzenegger, "Final Report: Use of Weather And Occupancy Forecasts For Optimal Building Climate Control - Part II : Demonstration ( OptiControl-II )," 2013.

15. L. Keviczky, R. Bars, J. Hetthéssy, and C. Bányász, "Introduction to MATLAB," Advanced Textbooks in Control and Signal Processing, 2019. 